\title{
Material Reutilization Cycles Across Industries and Production Lines
}

\author{
Friedrich A. Halstenberg, Jón G. Steingrímsson and Rainer Stark
}

\begin{abstract}
The concept of Industrial Symbiosis aims at organizing industrial activity like a living ecosystem where the by-product outputs of one process are used as valuable raw material input for another process. A significant method for the systematic planning of Industrial Symbiosis is found in input-output matching, which is aimed at collecting material input and output data from companies, and using the results to establish links across industries. The collection and classification of data is crucial to the development of synergies in Industrial Symbiosis. Public and private institutions involved in the planning and development of Industrial Symbiosis rely however on manual interpretation of information in the course of creating synergies. Yet, the evaluation and analysis of these data sources on Industrial Symbiosis topics is a tall order. Within this chapter a method is presented which describes value creation activities according to the Value Creation Module (VCM). They are assessed before they are integrated in Value Creation Networks (VCNs), where alternative uses for by-products are proposed by means of iterative input-output matching of selected value creation factors.
\end{abstract}

Keywords Circular economy • Industrial symbiosis • Industrial ecology • Value creation networks $\cdot$ Input-output matching

\section{Closing Material Cycles in Manufacturing}

Industrial sustainability is a topic which can be addressed from a range of angles, including not only from the usual product and process perspective, but also on the level of Value Creation Networks (VCNs).

\author{
F.A. Halstenberg $(\bowtie) \cdot$ J.G. Steingrímsson \\ Institute for Machine Tools and Factory Management, \\ Technische Universität Berlin, Berlin, Germany \\ e-mail: f.halstenberg@tu-berlin.de \\ R. Stark \\ Chair of Industrial Information Technology, Institute for Machine-tools and Factory \\ Management, Technische Universität Berlin, Berlin, Germany \\ (C) The Author(s) 2017 \\ R. Stark et al. (eds.), Sustainable Manufacturing, Sustainable Production, \\ Life Cycle Engineering and Management, DOI 10.1007/978-3-319-48514-0_11
}


The concept of a Circular Economy, which seeks to decouple global economic development from finite resource consumption, has attracted a lot of attention in recent years (Ellen MacArthur Foundation 2015). Circular Economy is an umbrella term for different material recovery techniques such as reusing, remanufacturing, and recycling (Ellen MacArthur Foundation 2015), as well as frameworks for closed material systems, such as the Blue Economy (Pauli 2010), Industrial Ecology (IE) (Frosch and Gallopoulos 1989), and Industrial Symbiosis (Chertow 2007). Within these frameworks, one can distinguish whether the material has been recovered from an intentionally manufactured product at the point of its end-of-life (EOL), or as a by-product (an unintended derivative of the production process). The waste framework directive of the European Commission specifies the hierarchy of waste from the least favourable option to the most favourable option (landfilling, energy recovery, recycling, reuse/remanufacturing, minimization, and prevention) (European Commission 2008). Since the term 'waste' conveys no or little value, the authors opt for the term 'by-product,' with its reference to originally unintended derivatives of manufacturing resulting separately from the desired product through industrial processes.

The term Industrial Ecology (IE) was coined by Frosch and Gallopoulos to depict the design of manufacturing entities analogous to natural ecosystems (Frosch 1992). As a sub-discipline of IE, Industrial Symbiosis is concerned with resource optimization among collocated companies (Jacobsen 2006). Industrial Symbiosis brings together traditionally separate industries into a collective approach for competitive advantage involving physical exchange of materials, energy, water, and/or by-products (Chertow 2000). In other words, Industrial Symbiosis aims at organizing industrial activity like that of a living ecosystem, where the by-product outputs of one process are used as valuable raw material input for another process. In an ideal Industrial Symbiosis, waste material (by-products) and energy are shared or exchanged between the actors of the system, therein reducing the net consumption of raw material and energy inputs, and thus the generation of waste and emissions (Sokka 2011). The geographic co-location of production plants with possible synergies in terms of waste streams, furthermore, serves to facilitate the exchange of the physical flows that are involved (Duflou et al. 2012). One aspect of the Factory of the Future, described by Herrmann et al. entails the symbiotic integration of factories into their surroundings (Herrmann et al. 2014). Cerdas et al. introduce the concept of a Circulation Factory, combining manufacturing with remanufacturing and recycling into an integrated system (Cerdas et al. 2015).

The term 'eco-industrial park' (EIP) describes, in a general sense, an industrial or a commercial area that is used by different companies. EIPs are networks comprising a variety of firms with an immediate geographical proximity to one another, where material exchange is carried out. An important precondition for an EIP is mutual trust, which seems to be a precondition to implementing common exchange relationships successfully (Bauer 2008; Hauff et al. 2012; Ludwig 2012). The EIP in Kalundborg, Denmark, is considered to be a seminal example in the literature on Industrial Symbiosis. The development of Industrial Symbiosis has been described as an evolutionary process in which a number of independent by-product exchanges have 
gradually evolved into a complex web of symbiotic interactions between five collocated companies and the local municipality (Ehrenfeld and Gertler 1997).

Results have shown that significant environmental savings are related to Industrial Symbiosis in Kalundborg (Jacobsen 2006). For example, three million $\mathrm{m}^{3}$ of water could be saved through recycling and reuse. The environmental benefits of Industrial Symbiosis have been quantified in numerous further cases (Kincaid and Overcash 2001; Chertow and Lombardi 2005). Although Industrial Symbiosis has developed into a notable research topic, its impact on actual industrial practice remains very modest (Chertow 2007). Efforts by public and private institutions have been made to improve the systematic planning and development of Industrial Symbiosis over the past decades (Lowe 2007). Practitioners moreover consider it crucial to finding ways of obtaining buy-ins from businesses - an essential step for success. Many practitioners have noted the significance of company champions (Chertow and Park 2016) as well as the importance of using the language of business (costs, revenues, risk, etc.) to generate this buy-in (Laybourn 2015). Duflou et al. argue that 'the most effective way of strengthening Industrial Symbiosis is to increase the economic motivation' (Duflou et al. 2012).

A significant method for the systematic planning of Industrial Symbiosis is inputoutput matching. It is aimed at collecting material input and output data of companies, and using the results to establish links across industries. As an outcome of the method, a resource input associated with one organization can be matched to a complementary resource output of another organization (Lowe 2007). In the case of a certain proximity of a match, an integrated input-output matching method can also be recommended for a further conversion or treatment process (Bin et al. 2015).

Regarding the support of input-output matching, a growing trend has surfaced, whereby the application of internet-based IT tools such as Synergie by International Synergies, or the Resource-eXchange-Platform as part of the ZeroWIN EU project have emerged to further promote coordination and exchanges. Additional tools include Knowledge-Based Decision Support System (Boyle and Baetz 1998), Dynamic Industrial Materials Exchange Tool (Shropshire et al. 2000), Match Maker! (Chertow 1997), Industrial Ecology Planning Tool (Nobel and Allen 2000), WasteX (Clayton et al. 2002), Industrial Ecosystem Development Project (Kincaid and Overcash 2001), Residual Utilization Expert System (Fonseca et al. 2005), Institute of Eco-Industrial Analysis Waste Manager (Sterr and Ott 2004), Industrie et Synergies Inter-sectorielles (Massard and Erkmann 2007), SymbioGIS (Massard and Erkmann 2009), and Core Resource for Industrial Symbiosis Practicioners (Laybourn and Morrissey 2009).

The collection and classification of data is crucial to the development of synergies in Industrial Symbiosis (Cecelja 2016). Public and private institutions involved in the planning and development of Industrial Symbiosis rely on manual interpretation of information in the course of personal communication and case-by-case analysis. Cecelja et al. (2014) report that in the course of their service offer, practitioners access and interpret data collected from the industry by combining it with further data stored in databases such as the following: 
- Proprietary databases built to monitor the activity of industry, e.g. industrial sectors, industrial volumes, planning and marketing datasets, and occasional project management technologies, such as environmental records, quality management practices, or

- Custom-made databases that offer access to case studies, e.g. Crisp system (Grant et al. 2010).

Bin et al. propose a big data analytics approach for developing industrial symbioses in large cities. The authors suggest that data can be acquired from structured or unstructured sources. Structured sources include company registration, waste exchange registry databases, the national pollutant emissions inventory, geographical information systems (e.g. Google Maps), lifecycle inventory databases, etc. Examples of unstructured data sources are financial reports, information from company websites, online news, social media, online encyclopaedias, and journal corpus (Bin et al. 2015).

The evaluation and analysis of these data sources regarding Industrial Symbiosis is of course challenging to say the least. Firstly, data has to be interpreted in the context of specific knowledge domains. Secondly, the resulting implications have to be evaluated in combination with available data about the surrounding value creation network (e.g. materials, technologies and objectives, environmental effects, economic and social benefits). Given increasing numbers of network participants, their dynamic behaviour within the network (e.g. inclusion of new technologies, inclusion of additional stages for by-product pre-processing, pre-treatment, transportation, and storage) and the resulting complexity of material streams, it becomes quite apparent that a systematic and thorough analysis through manual manipulation of data is outright impossible (Desrochers 2004; Mirata and Emtairah 2005). Furthermore, Grant et al. criticize the available datasets as outdated and incapable of assisting innovation (Grant et al. 2010).

In order to involve businesses in Industrial Symbiosis, online platforms for facilitating exchange of by-products have been provided. Industry organizations such as the United States Business Council for Sustainable Development (USBCSD), or facilitators such as National Industrial Symbiosis Programme (NISP), allow businesses a secure and common platform for discussing potential synergies through symbiosis (Chertow and Park 2016). In recent approaches, novel concepts such as ontology engineering have been introduced in matching tools and platforms for Industrial Symbiosis, since they can help to put tacit knowledge out there-essential for the mutual, nonmarket interactions required for Industrial Symbiosis (Cecelja et al. 2014; Cecelja 2016). Halstenberg et al. suggest employing organisational data systems such as Product Data Management Systems (PDM), Product Lifecycle Management (PLM), Enterprise Resource Management Systems (ERP). Utilizing these data for Input-Output Matching tools and platforms can add functionality to existing approaches (Halstenberg et al. 2016). 


\section{Method Design for Sustainable Manufacturing by Analysis of Value Creation Factors}

A number of different approaches exist which address the issue of Match-Making for Industrial Symbiosis. In this section, the method for designing in pursuit of resource efficient approaches stemming from the domain of sustainable manufacturing is presented, involving analysis of value creation factors. The method relies on the concept of the Value Creation Module (VCM), which will be explained in Sect. 2.1, followed by a description of the method (Sect. 2.2).

\subsection{The Value Creation Module (VCM)}

Any type of value creation activity can be characterised in terms of a so-called value creation module (VCM) (Seliger 2008). The VCM is depicted in Fig. 1. A VCM is composed by five Value Creation Factors (VCF): product, process, equipment, organisation and human. Networks and modules are conceivable at different levels of aggregation (Wiendahl et al. 2009) (e.g. grinding a turbine blade, assembling a turbine, building a power plant, and providing power for a community), each with sustainability indicators that are identical on all aggregation levels or relevant for the respective aggregation level. Effective and efficient VCFs must be identified, combined into promising VCMs and promoted.

Fig. 1 Value Creation Module (VCM) (Seliger 2008)

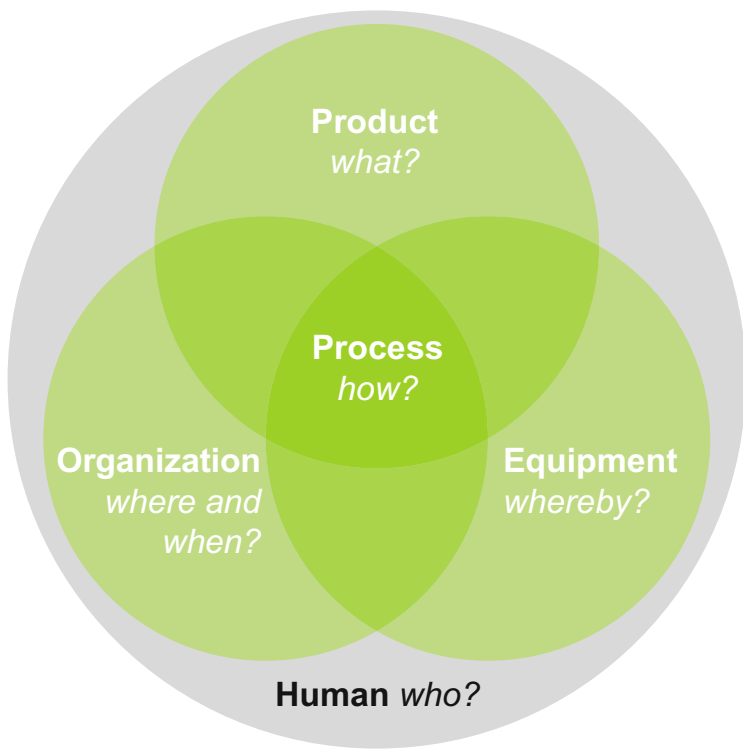


A Product represents a desired, manufactured output according to design requirements, specifications and standards (Laperrière and Reinhart 2014). A process is understood as a task that depicts how desired outputs are created from inputs. Equipment is the means to manufacture the products, e.g. machine tools, jigs and fixtures, tools and measuring equipment. The crucial precondition for factory operations are humans. They are the direct employees involved in value creation, using qualifications and training to that end (Westkämper 2006). The organisation represents the functional, spatial and temporal context in which manufacturing tasks are carried out and managed (Spur 1994).

\subsection{Description of the Method}

This sub-section highlights the procedure for the method of designing for sustainable manufacturing and thereby included resource efficiency by means of analysis of value creation factors. A flowchart of the procedure can be seen in Fig. 2. The goal of the method is to model and plan value creation networks in a sustainable manner with a specific focus on by-product exchanges in the sense of Industrial Symbiosis objectives.

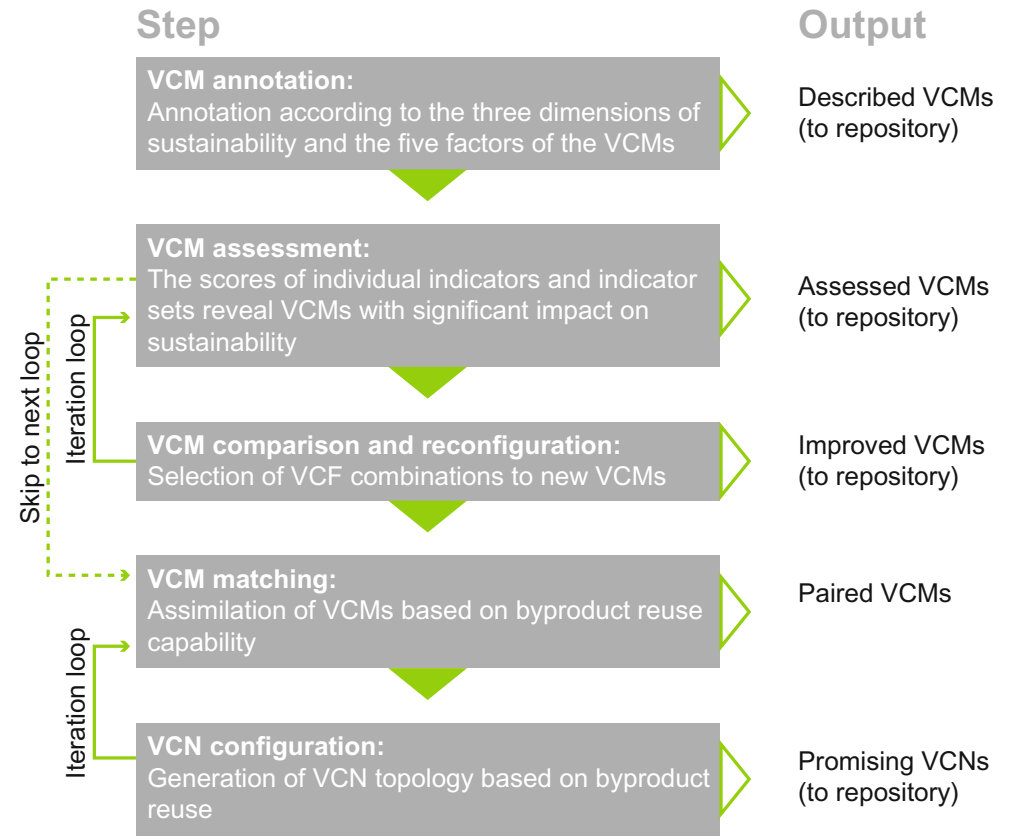

Fig. 2 Flowchart of the method for designing for sustainable manufacturing by means of analysis of value creation factors 
Firstly, VCMs are annotated, assessed and improved. This part of the method focused for that reason, on the specific processes and not on their network. Secondly, the method focuses on the network level. Here the individual VCMs are matched in order to form Value Creation Networks (VCNs).

The VCM (see also Sect. 2.1) provides a structured framework for the annotation of value creation activities in the first step of the method. It allows the integrating of various levels of aggregation from a single manufacturing tool and operations via manufacturing cells and systems, whole factories with national and international entrepreneurial conglomerates or knowledge generating communities (Wiendahl et al. 2009). As this method prescribes, VCMs are annotated according to the three pillars of sustainability as well as according to the five VCFs (product, process, equipment, human and organisation).

In order to gain general knowledge on the sustainability performance of the VCM, a VCM assessment is performed in the second step. The scores of individual indicators and indicator sets reveal which of the VCMs have a significant impact on sustainability. In order to reduce dependency on detailed performance data, a qualitative approach is used. This approach enables a rapid cross-industry assessment of VCMs, capable of showing concrete improvement potential. The VCM assessment is based on the Bellagio principles and is requisite for a dynamic shift between module and network perspective.

The third step, VCM comparison and reconfiguration of alternatives, is then performed in order to eliminate shortcomings of VCMs which have been identified through the VCM assessment. In this step of the method, alternative comparison and VCM reconfiguration are conducted. Next, alternative comparison is performed by comparing the VCM assessment scores for two or more different VCMs. All VCMs are then described according to a VCM annotation structure, where elements and elements instances are utilised. This is made possible through similarity matching between these elements and elements instances. Depending on the similarity score of the selected comparison elements, the VCM can be reconfigured and its sustainability performance enhanced. The comparison criteria are selectable based on the VCM annotation and a reference VCM.

Once the comparison criteria and the similarity matching threshold have been determined, the highest scoring VCMs are presented, based on the individual indicator sets. The indicator set score is based on the VCM assessment. The VCM reconfiguration is a process for improving a reference VCM by VCF substitution. $\mathrm{VCF}$ of higher scoring VCMs are used for the process.

Figure 3 presents a comparison between two VCMs, 'Bamboo frame manufacturing at PTZ' and 'SUW sharing platform'. The latter offers significant improvements in public reach, which when implemented as a 'Help for self-help bamboo frame manufacturing in Vietnam' presents an improved overall sustainability performance.

The method focuses on the network implementation of the previously annotated, assessed and reconfigured VCMs. All VCMs considered are now treated as black-boxes, and matched with the purpose of forming networks. A network can be formed and planned according to various goals. The method presented focuses on 


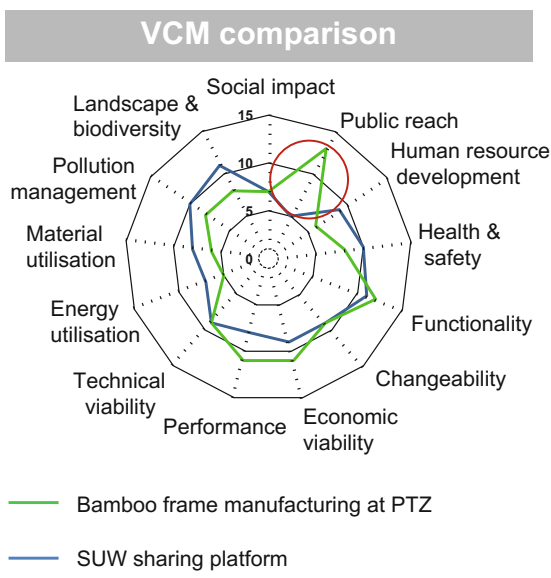

Fig. 3 VCM comparison and reconfiguration

\section{VCM after reconfiguration}

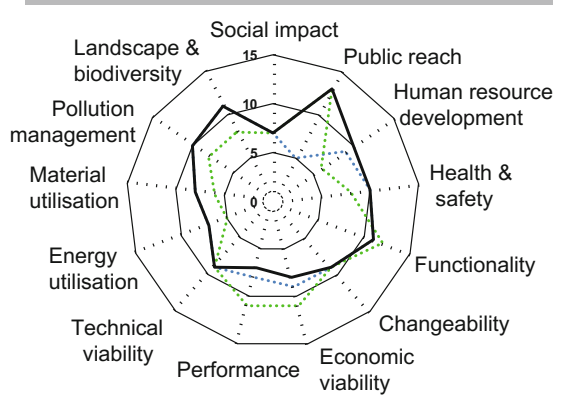

Bamboo frame manufacturing at PTZ SUW sharing platform

Help for selfhelp bamboo frame manufacturing in Vietnam

the aspect of creating symbiotic relationships among companies in the sense of an Industrial Symbiosis.

The process of VCM matching begins with a classification of the by-product, all the while ensuring representation in a manner that is appropriate to the various industries. For example, a by-product can be classified as a biomaterial or a technical material (metals, ceramics, organic polymers, composites, semi-conductors and advanced materials). In the next step, the by-product is annotated in terms of quantitative and qualitative information. In this process, the VCM is described in a more detailed manner through information embedded in the VCM ontology belonging to the VCF taxonomies for product, process and equipment. The goal is an annotation which ensures that a by-product of one manufacturing entity is described in a suitable manner so that it can find a suitable fit with another manufacturing entity. The material type classification, economic factors, environmental considerations and known reutilisation possibilities are all required (e.g. stream behaviour, material cost, level of toxicity, reutilization possibilities) in that pursuit.

A match of one VCM to another is performed by comparing the respective inand outputs. In order to establish possible usage, the by-product material stream is classified.

Moreover, in pursuit of identifying suitable relationships between VCMs within the considered VCN, an input-output matching approach is carried out to pair VCMs based on their by-products. For this purpose, a similarity algorithm is utilized. An important aspect of input-output matching is the range of matching since, depending on the type of description, different ranges are possible. In the case of a quantitative description, the pairing up can either be a 1-to-1 match or be located within a certain range. In the case of a qualitative matching, the inputs and outputs can be matched according to semantic descriptions. 
According to the VCM matches identified, suitable VCNs have to be configured in the next step. From a single VCM, pairs of VCMs are generated and a network is formed by moving with the flow of by-products. Having the role of a broker in place - that is, a neutral network administrator who has the responsibility of creating a VCN and identifying open interfaces for new VCMs creation-is seen as a useful function for the arrangement of the different VCMs in a network. Three tasks are then performed in order to establish the networks. First, a joint effort opportunity is to be detected and promoted by a broker, made through an online platform. Then the main features best suited to describing the joint effort are to be classified. Finally, rough planning for the network is to be conducted. Possible network partners and their ideal locations can then be identified. A VCN topology is created by selecting one VCM to act as an anchoring point and other VCMs arranged accordingly.

\section{References}

Bauer, J. 2008. Industrielle Ökologie: Theoretische Annäherung an ein Konzept nachhaltiger Produktionsweisen. Dissertation, University of Stuttgart.

Bin, Song, Yeo Zhiquan, Low Sze Jonathan, Derek K. Choong, Denis Kurle Jiewei, Felipe Cerdas, and Christoph Herrmann. 2015. A big data analytics approach to develop industrial symbioses in large cities. Procedia CIRP 29: 450-455.

Boyle, C.A., and B.W. Baetz. 1998. A prototype knowledge-based decision support system for industrial waste management: Part I. The decision support system. Waste Management 18(2): 87-97.

Cecelja, F. 2016. Ontology evaluation for reuse in the domain of process systems engineering. Comuputers \& Chemical Engineering 85: 177-187. doi:10.1016/j.compchemeng.2015.12.003.

Cecelja, F., T. Raafat, N. Trokanas, S. Innes, M. Smith, A. Yang, Y. Zorgios, A. Korkofygas, and A. Kokossis. 2014. e-Symbiosis: Technology-enabled support for industrial symbiosis targeting small and medium enterprises and innovation. Journal of Cleaner Production. doi:10.1016/j.jclepro.2014.08.051.

Cerdas, Felipe, Denis Kurle, Stefan Andrew, Sebastian Thiede, Christoph Herrmann, Yeo Zhiquan, Low Sze Jonathan, Song Bin Choong, and Sami Kara. 2015. Defining circulation factories - a pathway towards factories of the future. Procedia CIRP 29: 627-632.

Chertow, Marian R. 1997. The source of value: An executive briefing and sourcebook on industrial ecology. Journal of Industrial Ecology 2: 151-152. doi:10.1162/jiec.1997.1.2.151.

Chertow, Marian R. 2000. Industrial symbiosis: Literature and taxonomy. Annual Review of Energy and the Environment 25(1): 313-337. doi:10.1146/annurev.energy.25.1.313.

Chertow, Marian R. 2007. "Uncovering” industrial symbiosis. Journal of Industrial Ecology 11 (1): 11-30. doi:10.1162/jiec.2007.1110.

Chertow, Marian R., and D.R. Lombardi. 2005. Quantifying economic and environmental benefits of co-located firms. Environmental Science and Technology 39(17): 6535-6541. doi:10.1021/ es050050.

Chertow, Marian R., and Jooyoung Park. 2016. Scholarship and practice in industrial symbiosis: 1989-2014: Springer Gabler.

Clayton, Anthony, John Muirhead, and Han Reichgelt. 2002. Enabling industrial symbiosis through a web-based waste exchange. Greener Management International 2002(40): 93-106.

Desrochers, Pierre. 2004. Industrial symbiosis: The case for market coordination. Journal of Cleaner Production 12(8): 1099-1110. 
Directive 2008/98/EC of the European Parliament and of the Council of 19 November 2008 on waste and repealing certain Directives. European Commission. 312. Official Journal of the European Union L.

Duflou, Joost R., John W. Sutherland, David Dornfeld, Christoph Herrmann, Jack Jeswiet, Sami Kara, Michael Hauschild, and Karel Kellens. 2012. Towards energy and resource efficient manufacturing: A processes and systems approach. 5CIRP6 Annals-Manufacturing Technology 61(2): 587-609. doi:10.1016/j.cirp.2012.05.002.

Ehrenfeld, John, and Nicholas Gertler. 1997. Industrial ecology in practice: The evolution of interdependence at Kalundborg. Journal of Industrial Ecology 1(1): 67-79.

Ellen MacArthur Foundation. 2015. Towards a circular economy: Business rationale for an accelerated transition. http://www.ellenmacarthurfoundation.org/publications/towards-acircular-economy-business-rationale-for-an-accelerated-transition.

Fonseca, Daniel J., Eric Richards, Derek Williamson, and Gary P. Moynihan. 2005. A knowledge-based system for the recycling of non-hazardous industrial residuals in civil engineering applications. Expert Systems 22(1): 1-11.

Frosch, Robert A. 1992. Industrial ecology: A philosophical introduction. Proceedings of the National Academy of Sciences 89: 800-803.

Frosch, Robert A., and Nicholas E. Gallopoulos. 1989. Strategies for manufacturing. Scientific American 261(3): 144-152.

Grant, Gabriel B., Thomas P. Seager, Guillaume Massard, and Loring Nies. 2010. Information and communication technology for industrial symbiosis. Journal of Industrial Ecology 14(5): 740 753. doi:10.1111/j.1530-9290.2010.00273.x.

Halstenberg, Friedrich A., Kai Lindow, and Rainer Stark. 2016. Utilization of product lifecycle data from PLM systems in platforms for Industrial Symbiosis. In Proceedings of the 15th global conference on sustainable manufacturing.

Hauff, M. von, R. Isenmann, and G. Müller-Christ. 2012. Industrial ecology management: Nachhaltige Entwicklung durch Unternehmensverbünde: Springer Gabler.

Herrmann, Christoph, Christopher Schmidt, Denis Kurle, Stefan Blume, and Sebastian Thiede. 2014. Sustainability in manufacturing and factories of the future. International Journal of Precision Engineering and Manufacturing-Green Technology 1(4): 283-292.

Jacobsen, Noel B. 2006. Industrial symbiosis in Kalundborg, Denmark: a quantitative assessment of economic and environmental aspects. Journal of Industrial Ecology 10(1-2): 239-255.

Kincaid, Judy, and Michael Overcash. 2001. Industrial ecosystem development at the metropolitan level. Journal of Industrial Ecology 5(1): 117-126.

Laperrière, L., and G. Reinhart. 2014. CIRP encyclopedia of production engineering. New York: Springer.

Laybourn, P. 2015. G7 industrial symbiosis workshop: Faciltiy industrial symbiosis - the circular economy in action.

Laybourn, P., and M. Morrissey. 2009. The pathway to a low carbon sustainable economy: National Industrial symbiosis programme.

Lowe, Ernest. 2007. Eco-industrial park handbook for Asian developing countries. http://teclim. ufba.br/jsf/producaol/indigo\%20ecopk\%2001_18.PDF.

Ludwig, J. 2012. "Energieeffizienz durch Planung betriebsübergreifender Prozessintegration mit der Pinch-Analyse." Dissertation, Karslruher Institut für Technologie (KIT).

Massard, and Erkmann, eds. 2007. A regional industrial symbiosis methodology and its implementation in Geneva, Switzerland.

Massard, and Erkmann, eds. 2009. A web-GIS tool for industrial symbiosis: Preliminary results and perspectives.

Mirata, Murat, and Tareq Emtairah. 2005. Industrial symbiosis networks and the contribution to environmental innovation: The case of the Landskrona industrial symbiosis programme. Journal of Cleaner Production 13(10): 993-1002.

Nobel, C.E., and D.T. Allen. 2000. Using geographic information systems (GIS) in industrial water reuse modelling. Process Safety and Environmental Protection 78(4): 295-303. 
Pauli, Gunter. 2010. The blue economy. Our Planet. GREEN ECONOMY. Making it work. The magazine of the United Nations Environment Programme, 24-26.

Seliger, Günther. 2008. Sustainable value creation nets. In Proceedings of the global conference on sustainable product development and life cycle engineering VI, Pusan, Korea, 2-7.

Shropshire, D.E., D.A. Cobb, P. Worhach, J.J. Jacobson, and S. Berrett. 2000. Demonstration of decision support tools for sustainable development: An application on alternative fuels in the greater Yellowstone-Teton Region. Bechtel National Incorporated.

Sokka, Laura. 2011. Local systems, global impacts: Using life cycle assessment to analyse the potential and constraints of industrial symbiosis. Dissertation, University of Helsinki.

Spur, G. 1994. Handbuch der Fertigungstechnik: Band 6 - Fabrikbetrieb. München, Wien: Carl Hanser Verlag.

Sterr, Thomas, and Thomas Ott. 2004. The industrial region as a promising unit for eco-industrial development-Reflections, practical experience and establishment of innovative instruments to support industrial ecology. Journal of Cleaner Production 12(8): 947-965.

Westkämper, E. 2006. Einführung in die Organisation der Produktion. Berlin, Heidelberg, New York: Springer.

Wiendahl, H.-P., J. Reichardt, and P. Nyhuis. 2009. Handbuch Fabrikplanung. Konzept, Gestaltung und Umsetzung wandlungsfähiger Produktionsstätten. München: Hanser.

Open Access This chapter is licensed under the terms of the Creative Commons Attribution 4.0 International License (http://creativecommons.org/licenses/by/4.0/), which permits use, sharing, adaptation, distribution and reproduction in any medium or format, as long as you give appropriate credit to the original author(s) and the source, provide a link to the Creative Commons license and indicate if changes were made.

The images or other third party material in this chapter are included in the book's Creative Commons license, unless indicated otherwise in a credit line to the material. If material is not included in the book's Creative Commons license and your intended use is not permitted by statutory regulation or exceeds the permitted use, you will need to obtain permission directly from the copyright holder.

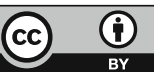

